\title{
Changes in Respiratory Muscle Strength Following Cardiac Rehabilitation for Prognosis in Patients with Heart Failure
}

\author{
Nobuaki Hamazaki ${ }^{1, *(1)}$, Kentaro Kamiya ${ }^{2}$, Shohei Yamamoto ${ }^{3,4}\left(\mathbb{D}\right.$, Kohei Nozaki ${ }^{1}$, \\ Takafumi Ichikawa ${ }^{1}$, Ryota Matsuzawa ${ }^{5}$, Shinya Tanaka ${ }^{6}$, Takeshi Nakamura $\left.{ }^{3}{ }^{(}\right)$, \\ Masashi Yamashita ${ }^{3}$, Emi Maekawa ${ }^{7}$, Kentaro Meguro ${ }^{7}$, Chiharu Noda ${ }^{7}$, \\ Minako Yamaoka-Tojo ${ }^{2}{ }^{\circ}$, Atsuhiko Matsunaga ${ }^{2}$ and Junya Ako ${ }^{7}$ \\ 1 Department of Rehabilitation, Kitasato University Hospital, Sagamihara 252-0375, Japan; \\ 0818.n.kohei@gmail.com (K.N.); takafumi@kitasato-u.ac.jp (T.I.) \\ 2 Department of Rehabilitation, Kitasato University School of Allied Health Sciences, \\ Sagamihara 252-0373, Japan; kamiken.pt@gmail.com (K.K.); myamaoka-circ@umin.ac.jp (M.Y.-T.); \\ atsuhikonet@gmail.com (A.M.) \\ 3 Department of Rehabilitation Sciences, Kitasato University Graduate School of Medical Sciences, \\ Sagamihara 252-0373, Japan; ap13338@st.kitasato-u.ac.jp (S.Y.); ap11327@st.kitasato-u.ac.jp (T.N.); \\ ap12344@st.kitasato-u.ac.jp (M.Y.) \\ 4 Department of Epidemiology and Prevention, Center for Clinical Sciences, National Center for Global \\ Health and Medicine, Tokyo 162-8655, Japan \\ 5 Department of Physiotherapy, School of Rehabilitation, Hyogo University of Health Sciences, \\ Kobe 650-8530, Japan; ryota122560@gmail.com \\ 6 Department of Rehabilitation, Nagoya University Medical School Hospital, Nagoya 466-8560, Japan; \\ tanashin.pt@gmail.com \\ 7 Department of Cardiovascular Medicine, Kitasato University School of Medicine, \\ Sagamihara 252-0373, Japan; emimae1207@med.kitasato-u.ac.jp (E.M.); \\ meguro@med.kitasato-u.ac.jp (K.M.); chiharu@med.kitasato-u.ac.jp (C.N.); jako@kitasato-u.ac.jp (J.A.) \\ * Correspondence: hamanobu0317@gmail.com; Tel.: +81-42-778-8413
}

Received: 7 March 2020; Accepted: 27 March 2020; Published: 30 March 2020

Abstract: Respiratory muscle weakness, frequently observed in patients with heart failure (HF), is reported as a predictor for poor prognosis. Although increased respiratory muscle strength ameliorates exercise tolerance and quality of life in HF patients, the relationship between changes in respiratory muscle strength and patient prognosis remains unclear. A total of 456 patients with HF who continued a 5-month cardiac rehabilitation (CR) were studied. We measured maximal inspiratory pressure $\left(\mathrm{PI}_{\max }\right)$ at hospital discharge as the baseline and five months thereafter to assess the respiratory muscle strength. Changes in $\mathrm{PI}_{\max }$ during the 5-month observation period $(\Delta \mathrm{PI} \max )$ were examined. We investigated the composite multiple incidence of all-cause death or unplanned readmission after 5-month CR. The relationship between $\triangle \mathrm{PI}_{\max }$ and the incidence of clinical events was analyzed. Over a median follow-up of 1.8 years, 221 deaths or readmissions occurred, and their rate of incidence was $4.3 / 100$ person-years. The higher $\Delta \mathrm{PI}_{\max }$ was significantly associated with lower incidence of clinical event. In multivariate Poisson regression model after adjustment for clinical confounding factors, $\triangle \mathrm{PI} \max$ remained a significant and independent predictor for all-cause death/readmission (adjusted incident rate ratio for $\Delta \mathrm{PI}_{\max }$ increase of $10 \mathrm{cmH}_{2} \mathrm{O}: 0.77,95 \%$ confidence interval: $0.70-0.86$ ). In conclusion, the changes in respiratory muscle strength independently predict the incidence of clinical events in patients with HF.

Keywords: change in respiratory muscle strength; heart failure; cardiac rehabilitation; prognosis; clinical event 


\section{Introduction}

Patients with heart failure (HF) frequently suffer from breathlessness during exercise, leading to exercise intolerance and decreased quality of life [1]. Exercise-related breathlessness partly results from respiratory muscle weakness, observed in approximately 30-50\% of patients with HF [2]. The respiratory muscle weakness is caused by muscular atrophy and/or decreased number of cross-bridges, resulting from the activation of inflammatory and neuroendocrine factors due to HF [2-5]. Additionally, several studies have demonstrated that respiratory muscle weakness is an independent predictor of exercise intolerance, ventilatory inefficiency during exercise, and poor prognosis of patients with HF $[6,7]$. However, the influence of longitudinal changes in respiratory muscle strength on prognostic outcomes remains unclear.

Conversely, comprehensive cardiac rehabilitation including exercise training, medication administration, nutritional management, and correcting lifestyle behavior is recognized as one of the key treatment strategies to prevent HF recurrence and to improve prognosis of patients with HF [8]. Furthermore, respiratory muscle training is reported to increase respiratory muscle strength and consequently improve exercise tolerance and quality of life in HF patients [9]. Hence, the current guideline on preventive cardiology and rehabilitation has recommended that respiratory training should be prescribed to patients with HF with exercise intolerance and respiratory muscle weakness in addition to the usual exercise training [10]. However, the effect of increased respiratory muscle strength on prognosis is unclear, although decreased respiratory muscle strength is reportedly associated with HF severity [11]. Our hypothesis was that the changes in respiratory muscle strength might potentially be a useful marker to assess the clinical status of HF as well as a surrogate marker to predict outcomes in patients with HF.

Therefore, this study aimed to investigate the relationship between changes in respiratory muscle strength following cardiac rehabilitation and the incidence of adverse clinical events in patients with HF.

\section{Materials and Methods}

\subsection{Study Design and Population}

This is a single-center observational study conducted to review a cohort of consecutive patients with HF who were admitted to Kitasato University Hospital for HF treatment and underwent a 5-month cardiac rehabilitation during hospitalization and after hospital discharge from May 2009 to December 2017. Patients who had received thoracic or open-heart surgery within the last three months or had chronic diseases of respiratory systems were excluded from the study. Comprehensive cardiac rehabilitation consisted of supervised exercise training and education on self-management including medication, nutrition, and physical activity, based on the statement from the Japanese Circulation Society [12]. Blood examinations and echocardiograms at hospital discharge were considered as baseline data. We also assessed pulmonary and respiratory muscle functions at baseline and at the end of the 5 -month cardiac rehabilitation. Events of all-cause mortality or all-cause unplanned readmission after the 5-month cardiac rehabilitation were considered as the primary end-point of this study. Data on all variables were obtained from an electronic database. The study protocol was approved by the Kitasato Institute Clinical Research Review Board (KMEO B18-075, September 4, 2018) and was performed according to the ethical guidelines of the Declaration of Helsinki.

\subsection{Patient Characteristics}

Data on age, gender, body mass index (BMI), HF severity assessed by the New York Heart Association functional classification (NYHA class), smoking history, medications, and medical history such as hypertension, diabetes mellitus, dyslipidemia, chronic kidney disease, or atrial fibrillation were obtained from medical records upon study participation. Routine laboratory analysis included hemoglobin and serum albumin as well as plasma brain natriuretic peptide (BNP). The estimated glomerular filtration rate (eGFR) was determined by serum creatinine levels. The left ventricular 
ejection fraction (LVEF) was also measured on echocardiograms using the 2D method. The AHEAD score was used to assess the patients' risk stratification and was calculated by assigning one point to the patient for each of the following factors: A: atrial fibrillation, $\mathrm{H}$ : hemoglobin $<13 \mathrm{~g} / \mathrm{dL}$ for men and $12 \mathrm{~g} / \mathrm{dL}$ for women, E: elderly (age $>70$ years), A: abnormal renal parameters (creatinine $>130 \mu \mathrm{mol} / \mathrm{dL}$ ), and D: diabetes mellitus [13]. The functional capacity was measured using the 6-min walk distance according to standard guidelines [14].

\subsection{Pulmonary and Respiratory Muscle Functions}

To assess the pulmonary function, spirometry without bronchodilator was performed to measure forced vital capacity (FVC) and forced expiratory volume in $1 \mathrm{~s}\left(\mathrm{FEV}_{1}\right)$ using a spirometer (Autospiro AS-507, Minato Medical Science, Osaka, Japan), and their percentages were calculated relative to the predictive values issued by the Japanese Respiratory Society [15]. To assess the respiratory muscle function, we measured the maximal inspiratory pressure $\left(\mathrm{PI}_{\max }\right)$ using a pressure transducer (Autospiro AAM-377, Minato Medical Science, Osaka, Japan) connected to the spirometer, according to the joint statement of the American Thoracic Society and European Respiratory Society [16]. In the measurement of $\mathrm{PI}_{\max }$, patients in a sitting position were instructed to hold a 25-mm-diameter flanged mouthpiece in their mouth and perform a 3-s forced inspiration from the level of maximal expiration. PI $I_{\max }$ was determined by the average value of the maximum pressure over a 1-s period during the 3-s forced inspiration. In this study, $\mathrm{PI}_{\max }$ was expressed as its absolute value, although it showed negative pressure for atmospheric pressure. The measurements were performed three times, and the maximum value in $\mathrm{PI}_{\max }$ was accepted for analysis. We also calculated percentage $\mathrm{PI}_{\max }\left(\% \mathrm{PI}_{\max }\right)$ relative to the predictive value that was estimated using each age, gender, height, and body weight [17]. The \% $\mathrm{PI}_{\max }$ of $<70 \%$ was defined as respiratory muscle weakness based on previous reports in patients with HF $[2,7,18]$.

\subsection{End-Points}

The primary end-point of this study was a composite of multiple all-cause clinical events including all-cause death and/or all-cause unplanned readmission identified through medical chart review. The secondary end-point was the composite of multiple cardiovascular events including cardiovascular death and/or unplanned readmission due to cardiovascular disease. We counted the number of these events after the end of the 5-month cardiac rehabilitation. The time period for these events was also calculated as the number of days from the end of the 5-month cardiac rehabilitation to the date of the events.

\subsection{Cardiac Rehabilitation Program}

All patients received comprehensive cardiac rehabilitation during hospitalization and after hospital discharge for five months. Cardiac rehabilitation was initiated when the HF condition was stabilized from the intensive care unit or general wards [12]. The median duration of cardiac rehabilitation initiation from hospitalization for all of studied patients was three days. In the acute phase, we facilitated mobilization and/or ambulation under the monitoring of electrocardiogram (ECG) and vital signs [12]. If patients were able to walk approximately $200 \mathrm{~m}$ with independence, they proceeded to inpatient exercise training with the low-moderate intensity $[19,20]$. Before hospital discharge, cardiologists and medical staff educated patients about self-management including medication, nutrition, and physical activity, and instructed encouragement to participate in outpatient cardiac rehabilitation at least once a week and perform 3-5/week of self-exercise. In outpatient cardiac rehabilitation, exercise training included a 5-min warm-up, 20-40-min aerobic training using a treadmill or bicycle ergometer, and 3-min cool-down periods [19]. Patients also received counselling about lifestyle in ambulatory visits. All exercise training sessions, both inpatient and outpatient, were supervised by trained nurses or physiotherapists, with continuous monitoring assessment. 


\subsection{Statistical Analysis}

Clinical variables before and after the 5-month cardiac rehabilitation were compared using the paired Student's $t$-test or the Wilcoxon signed rank test, as appropriate. We examined the changes in $\mathrm{PI}_{\max }$ from baseline to five months post-rehabilitation $\left(\triangle \mathrm{PI} \mathrm{I}_{\mathrm{max}}\right)$. Patients were divided into two groups based on whether $\Delta \mathrm{PI}_{\max }$ was positive, and differences in baseline clinical variables were compared between the two groups using the Student's unpaired $t$-test if parametric, the Mann-Whitney $U$-test if non-normally distributed for continuous variables, and the Chi-square or Fisher's exact test for categorical variables, as appropriate. The Kruskal-Wallis test and Fisher's exact test were also used to assess the differences in baseline characteristics and outcomes during the study period based on the time point (years) of study participation. Relationships between $\Delta \mathrm{PI}_{\max }$ and clinical end-points were analyzed using the Kaplan-Meier method with the log-rank test. To estimate the association between $\Delta \mathrm{PI}_{\max }$ and a composite of multiple hospitalization and/or death due to all-cause or cardiovascular events, univariate and multivariate Poisson regression models were used. Adjusted incident rate ratios (IRRs) were estimated by analyzing $\Delta \mathrm{PI}_{\max }$ as a categorical (positive of $\Delta \mathrm{PI}_{\max }$ ) or continuous variable (unit increase in $10 \mathrm{cmH}_{2} \mathrm{O}$ of $\mathrm{PI}_{\max }$ ) in separate models. The following clinical confounders at the end of the 5-month cardiac rehabilitation were used as covariates in multivariate analyses: age, sex, BMI, NYHA class, AHEAD score, BNP, the years of study participation, and PI $\mathrm{max}_{\max }$. For missing data on confounders, we performed multiple imputation using the chained equation method, assuming that analyzed data were missing at random. To combine the results from 20 imputed datasets for analysis, Rubin's formula was used. Time for the Poisson regression models started at the end of the 5-month cardiac rehabilitation. Restricted cubic spline curves with three knots were also used to determine the association between $\Delta \mathrm{PI}_{\max }$ and clinical events. Subgroup analyses of $\Delta \mathrm{PI}_{\max }$ in various subgroups relevant to the HF prognosis were performed to assess the potential effect modification on the association of $\Delta \mathrm{PI}_{\max }$ with clinical events. Trend relationships of clinical events with categories of $\Delta \mathrm{PI}_{\max }$ per $10 \mathrm{cmH}_{2} \mathrm{O}$ were examined using the Cochran-Armitage analysis. We also estimated the association between changes in clinical variables following cardiac rehabilitation and all-cause clinical events using multivariate Poisson regression models for each variable. The IRRs were analyzed with meaningful unit change in each variable. To compare the predictive capability of $\Delta \mathrm{PI}_{\max }$ and the other significant variables in multivariate Poisson analysis for clinical events, the C-index was calculated using multivariate logistic regression models adjusted for confounders used in the Poisson regression model. Continuous variables were reported as the mean \pm standard deviation or median with interquartile range, and categorical variables were expressed as patient numbers and their percentages. A two-tailed $P$ value of $<0.05$ was considered significant. All analyses were performed using SPSS 25.0 (IBM, Armonk, NY), Stata version 15.1 (Stata Corp., College Station, TX) and R version 3.1.2 (R Foundation for Statistical Computing, Vienna, Austria).

\section{Results}

\subsection{Patient Characteristics}

The potential study population consisted of 1570 consecutive patients who continued the 5-month cardiac rehabilitation, and those who had received thoracic surgery within the last three months $(n=393)$ or had chronic respiratory diseases $(n=140)$ were excluded from the study. Patients who could not perform the respiratory muscle function test during the observation period $(n=581)$ were also excluded. Consequently, 456 patients with HF were included for analysis in this study.

Overall $\mathrm{PI}_{\max }$ increased significantly after the 5-month cardiac rehabilitation (Table S1) with positive changes in $\mathrm{PI}_{\max }$ observed in 326 patients (71.5\%). Table 1 shows the baseline patient characteristics in the two groups based on positive changes in $\mathrm{PI}_{\max }$. The positive change in $\mathrm{PI}_{\max }$ was significantly associated with lower BNP and $\mathrm{PI}_{\max }$ and higher prevalence of respiratory muscle weakness at the baseline. However, no statistical differences in other baseline patient characteristics were observed between the two groups. Table S2 shows the differences in baseline characteristics, 
treatment, and outcomes during the study period based on the time point (years) of study participation. The time point was significantly associated with age, use of diuretics, frequency of outpatient cardiac rehabilitation, and incidence of all-cause events, but not with use of ACE-I/ARB and beta-blockers, change in $\mathrm{PI}_{\max }$, and incidence of cardiovascular events.

Table 1. Baseline patient characteristics in the two groups based on change in $\mathrm{PI}_{\max }$.

\begin{tabular}{|c|c|c|c|c|}
\hline Groups & Overall & $\Delta \mathrm{PI}_{\max } \leq 0 \mathrm{cmH}_{2} \mathrm{O}$ & $\Delta \mathrm{PI}_{\max }>0 \mathrm{cmH}_{2} \mathrm{O}$ & $p$ Value \\
\hline$n$ & 456 & 130 & 326 & \\
\hline Age, y.o. & $68(57-75)$ & $69(59-74)$ & $67(55-75)$ & 0.285 \\
\hline \multicolumn{5}{|l|}{ Gender, $n(\%)$} \\
\hline Female & 144 (31.6) & $38(29.2)$ & $106(32.5)$ & 0.577 \\
\hline Male & $312(68.4)$ & $92(70.8)$ & $220(67.5)$ & \\
\hline $\mathrm{BMI}, \mathrm{kg} / \mathrm{m}^{2}$ & $23.0 \pm 4.1$ & $22.8 \pm 3.7$ & $23.1 \pm 4.3$ & 0.478 \\
\hline HR, beats/min & $82 \pm 23$ & $84 \pm 25$ & $81 \pm 22$ & 0.224 \\
\hline $\mathrm{sBP}, \mathrm{mm} \mathrm{Hg}$ & $123 \pm 29$ & $123 \pm 32$ & $123 \pm 28$ & 0.839 \\
\hline $\mathrm{dBP}, \mathrm{mm} \mathrm{Hg}$ & $72 \pm 19$ & $72 \pm 21$ & $71 \pm 19$ & 0.638 \\
\hline \multicolumn{5}{|l|}{ Medical History, $n(\%)$} \\
\hline Ischemic Heart Disease & $240(52.6)$ & $72(55.4)$ & $168(51.5)$ & 0.469 \\
\hline Cardiomyopathy & $95(20.8)$ & $25(19.2)$ & $70(21.5)$ & 0.702 \\
\hline Atrial Fibrillation & 79 (17.3) & $29(22.3)$ & $50(15.3)$ & 0.099 \\
\hline Hypertension & $298(65.4)$ & $89(68.5)$ & $209(64.1)$ & 0.446 \\
\hline Dyslipidemia & $292(64.0)$ & $88(67.7)$ & $204(62.6)$ & 0.332 \\
\hline Diabetes Mellitus & $174(38.2)$ & $49(37.7)$ & $125(38.3)$ & 0.915 \\
\hline Chronic Kidney Disease & $261(57.4)$ & $79(60.8)$ & $182(56.0)$ & 0.401 \\
\hline Prior Admission for $\mathrm{HF}, n(\%)$ & $101(22.1)$ & $34(26.2)$ & $67(20.6)$ & 0.212 \\
\hline \multicolumn{5}{|l|}{ NYHA Class, $n(\%)$} \\
\hline II & $353(77.8)$ & $103(80.5)$ & $250(76.7)$ & 0.452 \\
\hline III & $101(22.2)$ & $25(19.5)$ & $76(23.3)$ & \\
\hline LVEF, \% & $46.3 \pm 15.2$ & $46.4 \pm 14.7$ & $46.3 \pm 15.4$ & 0.967 \\
\hline \multicolumn{5}{|l|}{ LVEF groups, $n(\%)$} \\
\hline$<40 \%$ & $148(33.2)$ & $45(35.2)$ & $103(32.4)$ & 0.806 \\
\hline $40-50 \%$ & $189(42.4)$ & $54(42.2)$ & $135(42.5)$ & \\
\hline$>50 \%$ & $109(24.4)$ & $29(22.7)$ & $80(25.2)$ & \\
\hline Smoking History, $n(\%)$ & $259(56.8)$ & $77(59.2)$ & $182(55.8)$ & 0.531 \\
\hline Pack-Years & $9.0(0.0-35.0)$ & $10.0(0.0-40.0)$ & $8.3(0.0-33.0)$ & 0.401 \\
\hline \multicolumn{5}{|l|}{ Medications, $n(\%)$} \\
\hline ACE-I or ARB & $392(86.0)$ & $116(89.2)$ & $276(84.7)$ & 0.234 \\
\hline Beta-Blockers & $374(82.0)$ & $108(83.1)$ & $266(81.6)$ & 0.788 \\
\hline Diuretic & $308(67.5)$ & $92(70.8)$ & $216(66.3)$ & 0.377 \\
\hline Hemoglobin, g/dL & $12.8 \pm 2.3$ & $13.0 \pm 2.5$ & $12.7 \pm 2.2$ & 0.168 \\
\hline Albumin, g/dL & $3.7 \pm 0.5$ & $3.7 \pm 0.5$ & $3.7 \pm 0.5$ & 0.837 \\
\hline Creatinine, $\mathrm{g} / \mathrm{dL}$ & $0.98(0.80-1.21)$ & $0.99(0.84-1.23)$ & $0.96(0.80-1.21)$ & 0.395 \\
\hline $\mathrm{eGFR}, \mathrm{mL} / \mathrm{min} / 1.73 \mathrm{~m}^{2}$ & $55.7 \pm 21.5$ & $55.1 \pm 22.2$ & $56.0 \pm 21.2$ & 0.685 \\
\hline $\mathrm{BNP}, \mathrm{pg} / \mathrm{mL}$ & $\begin{array}{c}227.7 \\
(113.0-435.4)\end{array}$ & $269.7(129.7-528.5)$ & $213.2(106.7-385.8)$ & 0.030 \\
\hline AHEAD Score & $1.6 \pm 1.2$ & $1.6 \pm 1.2$ & $1.6 \pm 1.2$ & 0.659 \\
\hline Six-min Walk Distance, $\mathrm{m}$ & $446(360-510)$ & $435(355-525)$ & $448(363-507)$ & 0.852 \\
\hline$\% \mathrm{FVC}, \%$ & $80.0 \pm 18.1$ & $80.6 \pm 19.4$ & $79.8 \pm 17.5$ & 0.661 \\
\hline $\mathrm{FEV}_{1} / \mathrm{FVC}, \%$ & $77.5 \pm 9.5$ & $76.8 \pm 8.0$ & $77.8 \pm 10.0$ & 0.349 \\
\hline $\mathrm{PI}_{\max }, \mathrm{cmH}_{2} \mathrm{O}$ & $58.5 \pm 27.1$ & $67.5 \pm 27.0$ & $54.9 \pm 26.4$ & $<0.001$ \\
\hline $\begin{array}{c}\text { Respiratory Muscle Weakness, } n \\
(\%)\end{array}$ & $148(33.0)$ & $26(20.3)$ & $122(38.1)$ & $<0.001$ \\
\hline
\end{tabular}

Values are mean $\pm \mathrm{SD}$, or median (interquartile range). ACE-I, angiotensin convertor enzyme inhibitor; ARB, angiotensin II receptor blocker; BMI, body mass index; $\mathrm{BNP}$, brain natriuretic peptide; $\mathrm{dBP}$, diastolic blood pressure; eGFR, estimated glomerular filtration rate; $\mathrm{FEV}_{1}$, forced expiratory volume in 1-s; FVC, forced vital capacity; HF, heart failure; HR, heart rate; LVEF, left ventricular ejection fraction; NYHA, New York Heart Association; PI $\mathrm{max}_{\text {, }}$ maximal inspiratory pressure; sBP, systolic blood pressure. 


\subsection{Relationships between Change in Respiratory Muscle Strength and Adverse Clinical Events}

A total of 221 all-cause clinical events and 132 cardiovascular events occurred during the median follow-up period of 1.8 years, and the incidence rate of all-cause events and cardiovascular events was 4.3/100 and 2.4/100 person-years, respectively. Figure 1 shows the Kaplan-Meier survival curves for the two groups. Positive changes in $\mathrm{PI}_{\max }$ were significantly associated with a lower incidence of all-cause clinical events (log-rank: $p=0.021)$ and cardiovascular events (log-rank: $p=0.003)$.
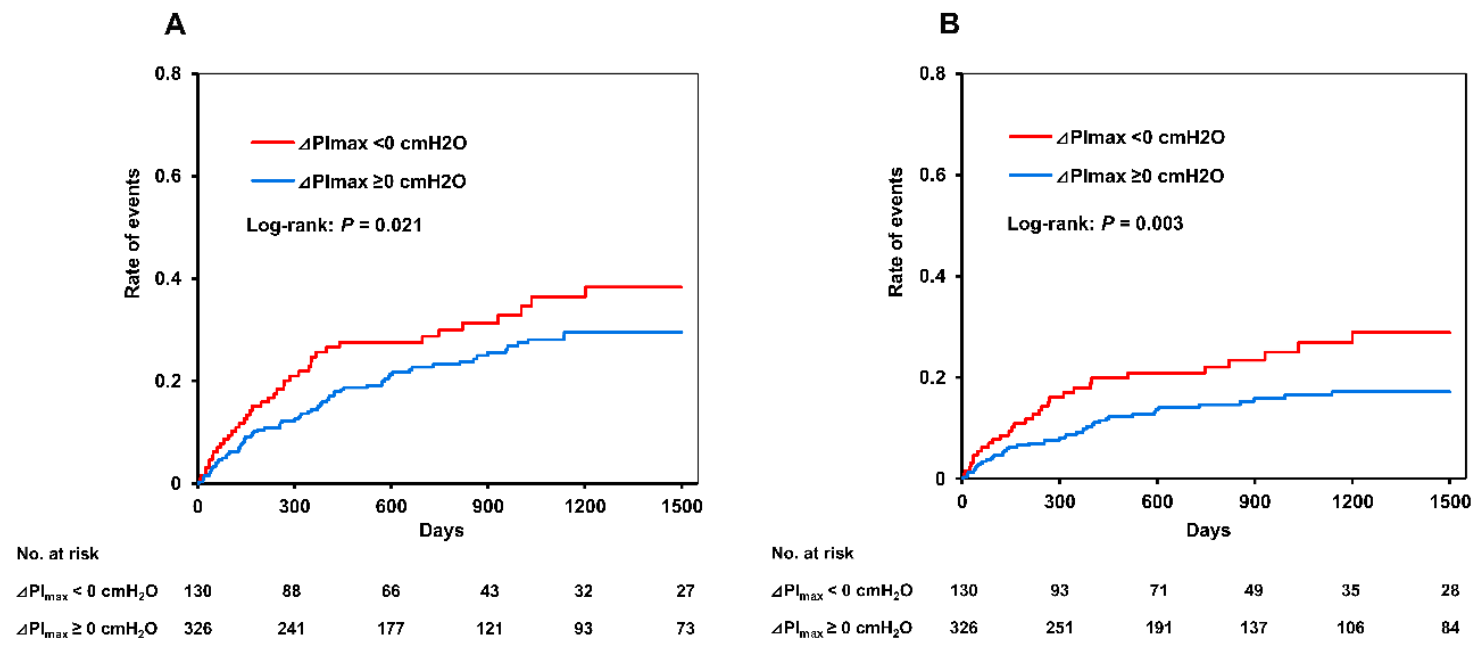

Figure 1. Kaplan-Meier survival curves of the association between change in respiratory muscle strength and clinical events. (A) All-cause events and (B) cardiovascular events; Red line, patients with $\Delta \mathrm{PI}_{\text {max }}<0 \mathrm{cmH}_{2} \mathrm{O}$; blue line, patients with $\Delta \mathrm{PI}_{\max } \geq 0 \mathrm{cmH}_{2} \mathrm{O}$. $\mathrm{PI}_{\max }$, maximal inspiratory pressure.

\subsection{Poisson Regression Models for Clinical Events}

Table 2 shows the results of the Poisson regression models of $\Delta \mathrm{PI}_{\max }$ for all-cause clinical events and cardiovascular events. In the univariate Poisson regression models, $\triangle \mathrm{PI} \max$ was significantly associated with all-cause clinical events (IRR: 0.75, 95\% confidence interval (CI): $0.69-0.82, p<0.001$ ) and cardiovascular events (IRR: 0.71,95\% CI: $0.63-0.79, p<0.001$ ). In the multivariate Poisson regression models adjusted for clinical confounding factors including age, gender, BMI, NYHA class, AHEAD score, BNP, time point of study participation, and $\mathrm{PI}_{\max }$ values at the end of the 5-month cardiac rehabilitation, $\triangle \mathrm{PI}_{\max }$ was detected as a significant and independent predictor for all-cause clinical events (adjusted IRR: 0.77, 95\% CI: 0.70-0.86, $p<0.001$ ) and cardiovascular events (adjusted IRR: 0.72, 95\% CI: 0.63-0.82, $p<0.001$ ). Positive changes in $\mathrm{PI}_{\max }$ were also independently associated with decreased all-cause and cardiovascular clinical events (Table 2). Cubic spline analyses clarified linear relationships between changes in $\mathrm{PI}_{\max }$ and all-cause or cardiovascular events (Figure 2).

Table 2. Poisson regression models of changes in $\mathrm{PI}_{\max }$ for adverse clinical events.

\begin{tabular}{|c|c|c|c|c|c|c|c|}
\hline & & \multicolumn{3}{|c|}{ Univariate Analysis } & \multicolumn{3}{|c|}{ Multivariate Analysis } \\
\hline & & IRR & $95 \%$ CI & $p$ Value & IRR & $95 \%$ CI & $p$ Value \\
\hline \multirow{2}{*}{\multicolumn{2}{|c|}{$\begin{array}{c}\text { All-Cause Events } \\
\Delta \mathrm{PI}_{\max } \text { increase of } 10 \mathrm{cmH}_{2} \mathrm{O}\end{array}$}} & & & & & & \\
\hline & & 0.75 & $0.69-0.82$ & $<0.001$ & 0.77 & $0.70-0.86$ & $<0.001$ \\
\hline \multirow[t]{2}{*}{$\Delta \mathrm{PI}_{\max }$} & $\leq 0 \mathrm{cmH}_{2} \mathrm{O}$ & 1.00 & Reference & & 1.00 & Reference & \\
\hline & $>0 \mathrm{cmH}_{2} \mathrm{O}$ & 0.52 & $0.40-0.68$ & $<0.001$ & 0.70 & $0.52-0.93$ & 0.014 \\
\hline \multicolumn{8}{|c|}{ Cardiovascular Events } \\
\hline \multicolumn{2}{|c|}{$\Delta \mathrm{PI}_{\max }$ increase of $10 \mathrm{cmH}_{2} \mathrm{O}$} & 0.71 & $0.63-0.79$ & $<0.001$ & 0.72 & $0.63-0.82$ & $<0.001$ \\
\hline \multirow[t]{2}{*}{$\Delta \mathrm{PI}_{\max }$} & $\leq 0 \mathrm{cmH}_{2} \mathrm{O}$ & 1.00 & Reference & & 1.00 & Reference & \\
\hline & $>0 \mathrm{cmH}_{2} \mathrm{O}$ & 0.39 & $0.28-0.55$ & $<0.001$ & 0.52 & $0.36-0.75$ & $<0.001$ \\
\hline
\end{tabular}

Multivariate analyses were adjusted for age, gender, BMI, time point of study participation, AHEAD score, NYHA

class, $\mathrm{BNP}$, and $\mathrm{PI}_{\max }$. IRR, incident rate ratio; $\mathrm{CI}$, confidence interval; $\mathrm{PI}_{\max }$, maximal inspiratory pressure. 

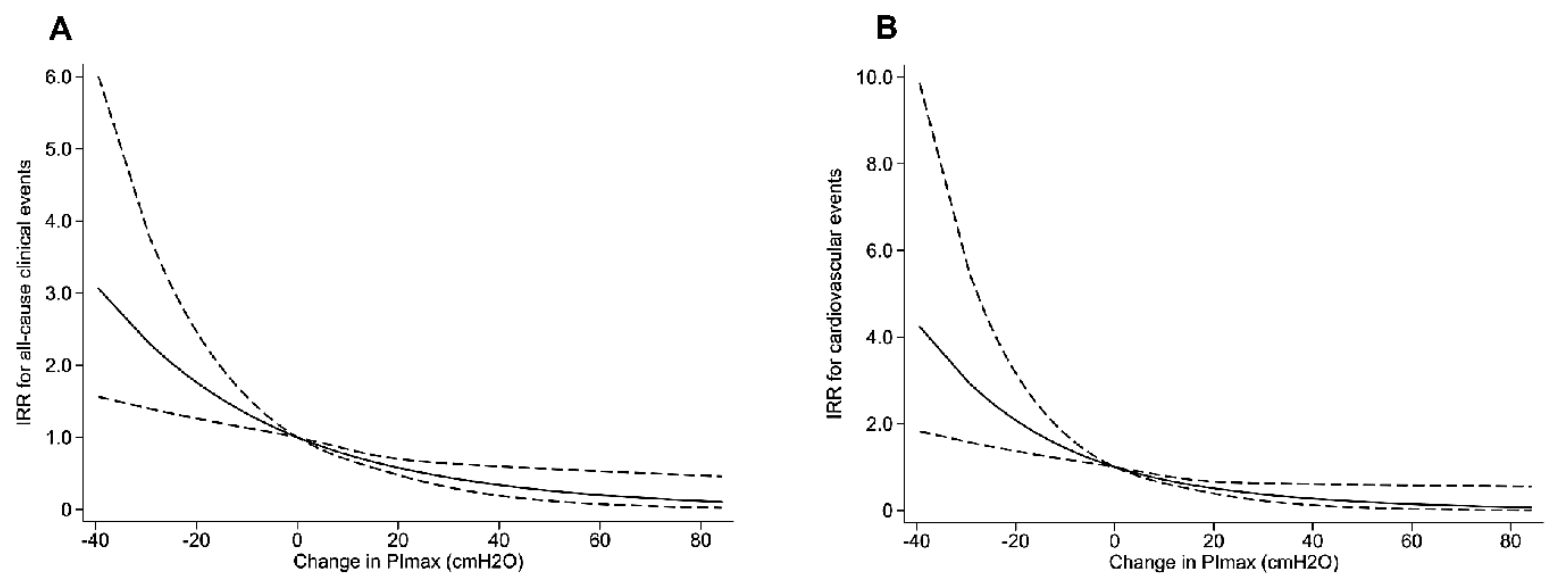

Figure 2. Cubic spline curves of crude relationships between change in respiratory muscle strength and incidence rate of end-points. (A) All-cause events and (B) cardiovascular events; Dash lines, $95 \%$ confidence interval. IRR, incident rate ratio; $\mathrm{PI}_{\max }$, maximal inspiratory pressure.

Figure 3 shows subgroup analyses of $\Delta \mathrm{PI}_{\max }$ for all-cause clinical events in various subgroups relevant to the HF prognosis. There were no significant interactions in the association of $\Delta \mathrm{PI}_{\max }$ with the incidence of adverse clinical events across the subgroups of aged $>75$ years, sex, NYHA class, and6MWD of $<400 \mathrm{~m}$ at the baseline. Conversely, subgroups with baseline BNP of $>200 \mathrm{pg} / \mathrm{mL}$ and respiratory muscle weakness showed significant interactions in the association of $\Delta \mathrm{PI}_{\max }$ with incidence of adverse clinical events. However, higher $\Delta \mathrm{PI}_{\max }$ was significantly associated with decreased adverse clinical events in all subgroups, even after adjusting for confounding factors used in the multivariate Poisson regression model.

\begin{tabular}{|c|c|c|c|c|}
\hline Subgroup & & No. of events (\%) & $\begin{array}{l}\text { Adjusted IRR per } 10 \mathrm{cmH}_{2} \mathrm{O} \\
\text { increase of } \mathrm{PI}_{\max }(95 \% \mathrm{cl})\end{array}$ & $\begin{array}{l}P \text { value for } \\
\text { interaction }\end{array}$ \\
\hline All patients & & $221(48)$ & - & \\
\hline Age & $\begin{array}{l}<75 \mathrm{yrs} \\
\geq 75 \mathrm{yrs}\end{array}$ & $\begin{array}{r}141(41) \\
80(69)\end{array}$ & 0 & 0.836 \\
\hline Sex & $\begin{array}{l}\text { Female } \\
\text { Male }\end{array}$ & $\begin{array}{r}66(46) \\
155(50)\end{array}$ & & 0.618 \\
\hline NYHA class & $\begin{array}{l}\text { II } \\
\text { III }\end{array}$ & $\begin{array}{r}150(42) \\
71(68)\end{array}$ & 0 & 0.923 \\
\hline BNP & $\begin{array}{l}<200 \mathrm{pg} / \mathrm{mL} \\
\geq 200 \mathrm{pg} / \mathrm{mL}\end{array}$ & $\begin{array}{r}84(43) \\
136(53)\end{array}$ & $\theta$ & 0.042 \\
\hline 6MWD & $\begin{array}{l}\geq 400 \mathrm{~m} \\
<400 \mathrm{~m}\end{array}$ & $\begin{array}{r}101(36) \\
98(64)\end{array}$ & $\begin{array}{l}0 \\
-1\end{array}$ & 0.061 \\
\hline $\begin{array}{l}\text { Respiratory muscle } \\
\text { weakness }\end{array}$ & $\begin{array}{l}\text { Absence } \\
\text { Presence }\end{array}$ & $\begin{array}{r}128(42) \\
93(61)\end{array}$ & 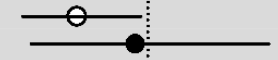 & 0.003 \\
\hline
\end{tabular}

Figure 3. Forest plots of hazard ratios for the association of change in respiratory muscle strength with all-cause clinical events according to major subgroups. Hazard ratios were adjusted for age, sex, BMI, AHEAD score, NYHA class, and BNP at the end of the 5-month cardiac rehabilitation. BMI, body mass index; BNP, brain natriuretic peptide; IRR, incident rate ratio; NYHA, New York Heart Association functional classification; $\mathrm{PI}_{\max }$, maximal inspiratory pressure; 6MWD, 6-min walk distance.

\subsection{Unadjusted Rates of Clinical Events}

The unadjusted event rate for $\Delta \mathrm{PI}_{\max }$ categories per $10 \mathrm{cmH}_{2} \mathrm{O}$ is shown in Figure 4 . The increase in $\mathrm{PI}_{\max }$ per $10 \mathrm{cmH}_{2} \mathrm{O}$ had significant trend relationships with a decreased rate of all-cause clinical 
events $(Z=2.975, p=0.003)$. There was also a statistically significant trend relationship between the $\mathrm{PI}_{\max }$ increase and decreased rate of cardiovascular events $(\mathrm{Z}=2.906, p=0.004)$, but the rate showed a fall with increased $\mathrm{PI}_{\max }$ and subsequent slight rise.

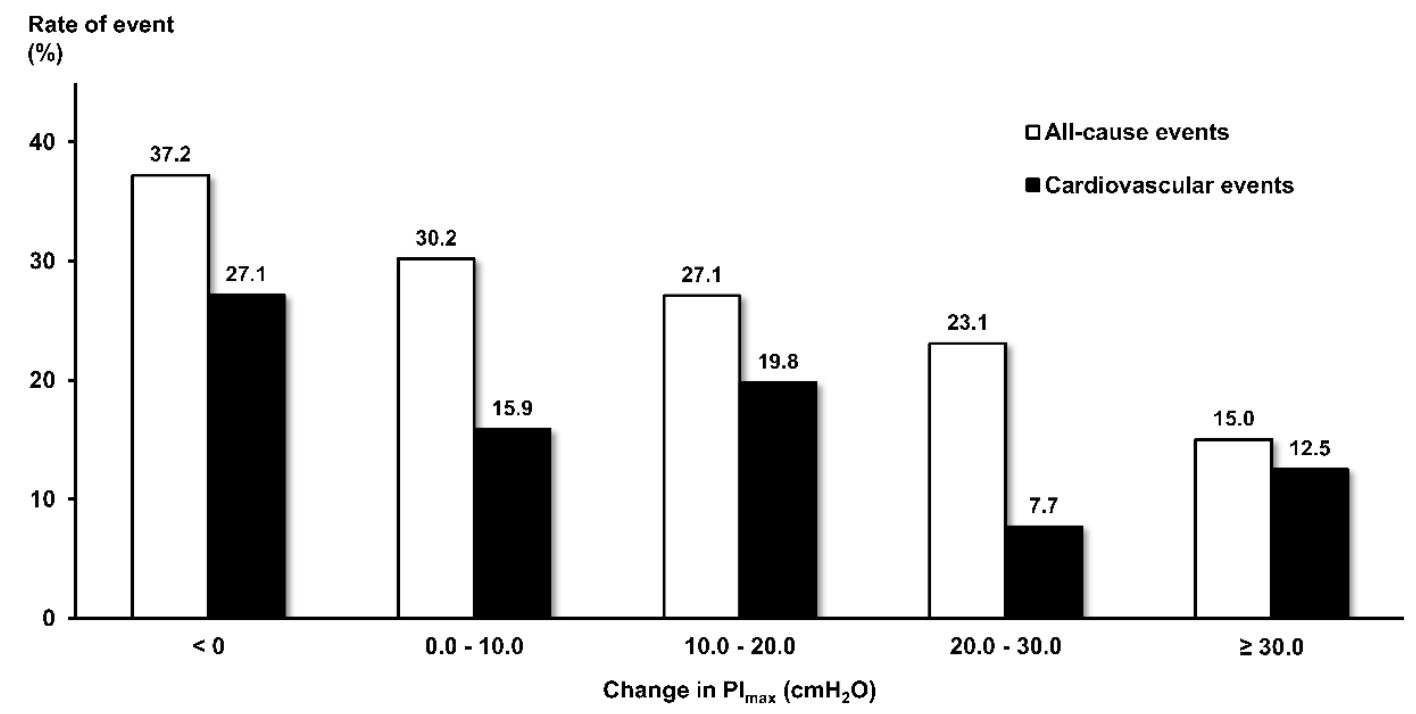

Figure 4. Unadjusted rates of all-cause clinical events and cardiovascular events according to categories of change in $\mathrm{PI}_{\max }$ per $10 \mathrm{cmH}_{2} \mathrm{O}$. White bars, all-cause events; black bars, cardiovascular events. $\mathrm{PI}_{\max }$, maximal inspiratory pressure.

\subsection{Predictive Significance of Changes in Clinical Variables Following Cardiac Rehabilitation for Clinical Events}

Table 3 shows the associations between changes in clinical variables and all-cause clinical events. The $\triangle 6 \mathrm{MWD}$ and $\Delta$ creatinine were significantly and independently associated with all-cause clinical events, but the changes in the other variables were not. Figure 5 shows the $C$-index of the predictive models for clinical events in $\triangle \mathrm{PI}_{\max }, \triangle 6 \mathrm{MWD}$, and $\triangle$ creatinine. Models were adjusted for age, sex, BMI, AHEAD score, NYHA class, and BNP at the end of 5-month cardiac rehabilitation. The C-index of $\Delta \mathrm{PI}_{\max }, \Delta 6 \mathrm{MWD}$, and $\Delta$ creatinine were 0.72 (95\% CI: 0.66-0.78), 0.71 (95\% CI: $0.65-0.77$ ), and 0.70 $(0.65-0.76)$, respectively, and there were no statistical differences between the three predictive models.

Table 3. Poisson regression models of changes in clinical variables for all-cause events.

\begin{tabular}{ccccc}
\hline & Adjusted IRR & Unit Changes & $\mathbf{9 5 \% ~ C I ~}$ & $p$ Value \\
\hline$\Delta$ BMI & 1.03 & $1 \mathrm{~kg} / \mathrm{m}^{2}$ & $0.95-1.11$ & 0.514 \\
$\Delta \mathrm{HR}$ & 1.00 & $5 \mathrm{beats} / \mathrm{min}$ & $0.99-1.01$ & 0.826 \\
$\Delta \mathrm{sBP}$ & 1.00 & $5 \mathrm{~mm} \mathrm{Hg}$ & $0.99-1.04$ & 0.856 \\
$\Delta \mathrm{dBP}$ & 1.04 & $5 \mathrm{~mm} \mathrm{Hg}$ & $0.99-1.10$ & 0.125 \\
$\Delta$ Hemoglobin & 0.96 & $1 \mathrm{~g} / \mathrm{dL}$ & $0.89-1.05$ & 0.379 \\
$\Delta$ Albumin & 0.98 & $0.1 \mathrm{~g} / \mathrm{dL}$ & $0.95-1.01$ & 0.265 \\
$\Delta$ Creatinine & 0.90 & $0.1 \mathrm{~g} / \mathrm{dL}$ & $0.89-0.91$ & $<0.001$ \\
$\Delta$ eGFR & 1.00 & $1 \mathrm{~mL} / \mathrm{min} / 1.73 \mathrm{~m}^{2}$ & $0.99-1.01$ & 0.825 \\
$\Delta$ BNP & 1.00 & $10 \mathrm{pg} / \mathrm{mL}$ & $1.00-1.01$ & 0.096 \\
$\Delta 6 \mathrm{MWD}$ & 0.93 & $10 \mathrm{~m}$ & $0.91-0.95$ & 0.019 \\
$\Delta \%$ FVC & 0.98 & $5 \%$ & $0.92-1.05$ & 0.595 \\
$\Delta$ FEV1/FVC & 1.04 & $5 \%$ & $0.95-1.14$ & 0.344 \\
\hline
\end{tabular}

IRRs were adjusted for age, gender BMI, time point of study participation, AHEAD score, NYHA class, and BNP. BMI, body mass index; BNP, brain natriuretic peptide; BP, blood pressure; CI, confidence interval; eGFR, estimated glomerular filtration rate; $\mathrm{FEV}_{1}$, forced expiratory volume in 1-s; FVC, forced vital capacity; IRR, incident rate ratio; $\mathrm{HR}$, heart rate; 6MWD, 6-min walk distance. 


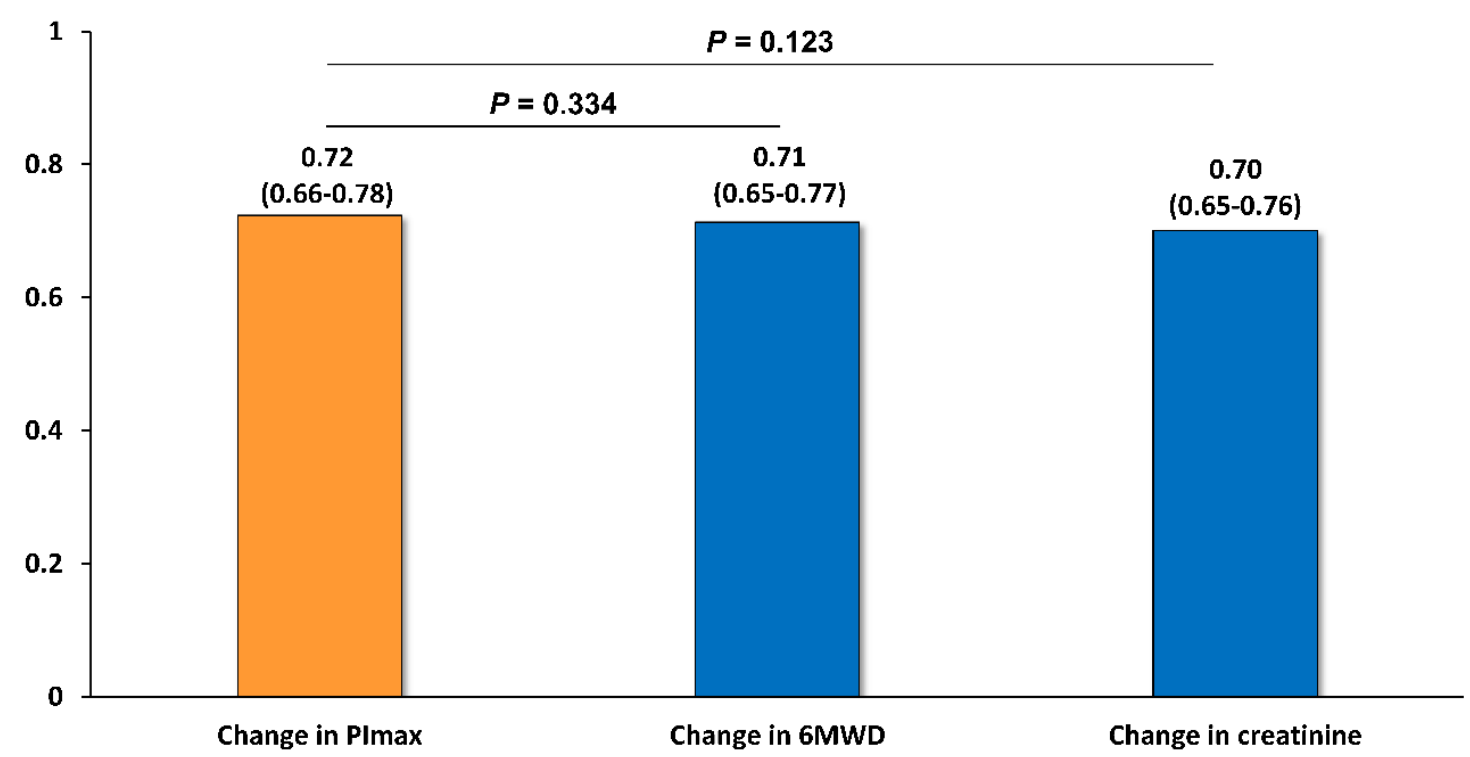

Figure 5. C-index of adjusted models of changes in $\mathrm{PI}_{\max }, 6 \mathrm{MWD}$, and creatinine for all-cause clinical events. Data, C-index (95\% CI). Models were adjusted for variables used in multivariate Poisson regression analyses. $\mathrm{PI}_{\max }$, maximal inspiratory pressure; 6MWD, 6-min walk distance.

\section{Discussion}

The novel findings in the present study are as follows. First, changes in respiratory muscle strength following the cardiac rehabilitation significantly and independently predicted the incidence of adverse clinical events in patients with HF. Second, positive changes in $\mathrm{PI}_{\max }$ of $10 \mathrm{cmH}_{2} \mathrm{O}$ following the cardiac rehabilitation were associated with $23 \%$ decrease of adverse clinical events.

To the best of our knowledge, this study is the first to demonstrate that the longitudinal change of respiratory muscle strength is a significant indicator of prognosis in patients with HF. Our previous study reported on the respiratory muscle strength as a significant predictor for prognosis in patients with HF with both reduced ejection fraction (HFrEF) and preserved ejection fraction (HFpEF) [7]. In general, decreased respiratory muscle strength is associated with reduced pulmonary function [6,21], a known risk factor for cardiovascular event including HF [22]. Conversely, Habedank and colleagues showed that $\mathrm{PI}_{\max }$, generally measured as a respiratory muscle function, was not an independent predictor of prognosis because it varied according to gender, BMI, and cachexia in patients with severe HFrEF [11]. A recent study has shown impaired respiratory muscle oxygenation during exercise in patients with HF, leading to breathlessness and decreased quality of life [23]. In the present study, the higher change in $\mathrm{PI}_{\max }$ was associated with lower respiratory muscle strength at the baseline. In addition, positive changes in $\mathrm{PI}_{\max }$ showed a trend relationship with declined clinical events, even after adjusting for gender, BMI, comorbidities, and HF severity. These relationships remained significant even in subgroups including elderly patients, those with lower functional capacity, or respiratory muscle weakness at baseline. These results suggest that the respiratory muscle weakness is likely to be improved by cardiac rehabilitation, and the repeated measurement of respiratory muscle strength might be more important than a single measurement to assess the clinical condition in patients with HF.

Several studies have indicated that increased respiratory muscle strength contributes to the improvement of respiratory muscle fatiguability, exercise tolerance, and quality of life $[9,24]$. Chiappa et al. reported the effects of inspiratory muscle training on peripheral blood flow during respiratory muscle fatigue stress in patients with HF [25]. They demonstrated that inspiratory muscle training improved peripheral muscle blood flow with decreased peripheral vascular resistance during respiratory muscle fatigue. In general, respiratory muscle fatigue induces sympathetic vasomotor outflow, resulting in the increased peripheral vascular resistance [26]. Conversely, increased inspiratory muscle strength augments tidal volume and consequently improves input to the pulmonary stretch 
receptor and autonomic nervous activity [27]. This improvement is documented in combination of reduced sympathetic activity and elevated parasympathetic activity, and thereby attenuates vascular resistance and increases peripheral blood flow [27]. These results are potential mechanisms of inspiratory muscle training to improve exercise tolerance and are likely correlated with our finding that increased respiratory muscle strength may improve the prognosis of patients with HF.

This study provides clinical implications that change in respiratory muscle strength is identified as a significant clinical marker for patients with HF. Previous studies have documented that the trajectory of $6 \mathrm{MWD}$ or renal function are associated with morbidity and mortality in these patients [28,29]. We revealed that the predictive capability of changes in respiratory muscle strength following cardiac rehabilitation was relatively higher or comparable to that of changes in 6MWD or renal function. In general, measurement of respiratory muscle strength is easy to perform in clinical practice. Therefore, respiratory muscle strength changes might be a useful marker to assess the effects of HF treatment. Furthermore, the respiratory muscle strength can be modified with exercise training including inspiratory muscle training in patients with HF $[9,30]$. Our results suggest the potential benefits of an increased respiratory muscle strength on the prognosis in patients with HF.

However, some limitations remain to be considered in the present study. First, as this was a single-center study that only included Japanese patients and the sample size was relatively small, whether these results can be applied to patients with HF in other hospitals or other populations remains to be elucidated. In addition, external validity could have been reduced, given that half of the potential study population was excluded from the analysis. Multivariate analyses were also performed using multiple confounders, which might increase the false-positive rates (type I error). Therefore, future multicenter studies are required to reveal the validity and reliability of change in respiratory muscle strength as predictors of prognosis in patients with HF. Second, this was not a randomized control trial. Hence, whether exercise training per se increased the respiratory muscle strength and decreased clinical events remains to be investigated. Further interventional study is required to investigate whether increased respiratory muscle strength due to exercise training improves the prognosis of patients with HF. Third, the period of data review was relatively long-term, 8.5 years, and the time point of study participation was associated with age, use of diuretics, and frequency of outpatient CR. Nevertheless, in the multivariate regression analyses, impact of the time point of study participation on relationships between change in respiratory muscle strength and outcomes was not observed. Fourth, in this study, while the respiratory muscle weakness was defined with $70 \%$ predicted value of $\mathrm{PI}_{\max }$, there was limited evidence using the \% $\mathrm{PI}_{\max }$ as a cut-off value for the weakness. As the more robust lower limit of normal values of PI $\mathrm{Imax}_{\text {ax }}$ has been suggested by the ATS/ERS statement in other patient groups [16], we consider it important to clarify the meaningful cut-off value of respiratory muscle weakness for patients with HF in the future.

\section{Conclusions}

Change in respiratory muscle strength following cardiac rehabilitation significantly and independently predicted clinical events in patients with HF. The $10 \mathrm{cmH}_{2} \mathrm{O}$ increase of $\mathrm{PI}_{\max }$ was significantly associated with a $23 \%$ decreased incidence of clinical events.

Supplementary Materials: The following are available online at http://www.mdpi.com/2077-0383/9/4/952/s1, Table S1: Changes in patient characteristics before and after the 5-month cardiac rehabilitation; Table S2: Differences in baseline characteristics, treatment, and outcomes during the study period based on the time point of study participation.

Author Contributions: Conceptualization, N.H. and K.K.; Methodology, N.H., K.K, S.Y., and J.A.; Validation, N.H., K.N., S.T., T.N., M.Y., E.M., K.M., C.N., M.Y.-T., and A.M.; Data curation, N.H., K.K., K.N., T.I., R.M., S.T., T.N., and M.Y.; Formal analysis, K.K. and S.Y.; Investigation, N.H., S.Y., T.I., R.M., E.M., K.M., C.N., M.Y.-T., and A.M.; Writing-Original Draft Preparation, N.H.; Writing-Review \& Editing, K.K., S.Y., K.N., T.I., R.M., S.T., T.N., M.Y., E.M., K.M., C.N., M.Y.-T., A.M., and J.A.; Visualization, N.H. and S.Y.; Supervision, J.A.; Project Administration, N.H., E.M., and J.A.; Funding acquisition, N.H. All authors have read and agreed to the published version of the manuscript. 
Funding: This work was supported by the Japan Society for the Promotion of Science Grant-in-Aid (JSPS KAKENHI, Grant Number JP19K1922).

Conflicts of Interest: The authors declare that there are no conflict of interest.

\section{References}

1. Hunt, S.A.; Baker, D.W.; Chin, M.H.; Cinquegrani, M.P.; Feldman, A.M.; Francis, G.S.; Ganiats, T.G.; Goldstein, S.; Gregoratos, G.; Jessup, M.L.; et al. ACC/AHA Guidelines for the Evaluation and Management of Chronic Heart Failure in the Adult: Executive Summary A Report of the American College of Cardiology/American Heart Association Task Force on Practice Guidelines (Committee to Revise the 1995 Guidelines for the Evaluation and Management of Heart Failure): Developed in Collaboration With the International Society for Heart and Lung Transplantation; Endorsed by the Heart Failure Society of America. Circulation 2001, 104, 2996-3007. [PubMed]

2. Kelley, R.C.; Ferreira, L.F. Diaphragm abnormalities in heart failure and aging: Mechanisms and integration of cardiovascular and respiratory pathophysiology. Heart Fail. Rev. 2017, 22, 191-207. [CrossRef] [PubMed]

3. Stassijns, G.; Gayan-Ramirez, G.; De Leyn, P.; Verhoeven, G.; Herijgers, P.; de Bock, V.; Dom, R.; Lysens, R.; Decramer, M. Systolic ventricular dysfunction causes selective diaphragm atrophy in rats. Am. J. Respir. Crit. Care Med. 1998, 158, 1963-1967. [CrossRef] [PubMed]

4. Laghi, F.; Tobin, M.J. Disorders of the respiratory muscles. Am. J. Respir. Crit. Care Med. 2003, 168, 10-48. [CrossRef] [PubMed]

5. Bowen, T.S.; Rolim, N.P.; Fischer, T.; Baekkerud, F.H.; Medeiros, A.; Werner, S.; Bronstad, E.; Rognmo, O.; Mangner, N.; Linke, A.; et al. Heart failure with preserved ejection fraction induces molecular, mitochondrial, histological, and functional alterations in rat respiratory and limb skeletal muscle. Eur. J. Heart Fail. 2015, 17, 263-272. [CrossRef] [PubMed]

6. Hamazaki, N.; Masuda, T.; Kamiya, K.; Matsuzawa, R.; Nozaki, K.; Maekawa, E.; Noda, C.; Yamaoka-Tojo, M.; Ako, J. Respiratory muscle weakness increases dead-space ventilation ratio aggravating ventilation-perfusion mismatch during exercise in patients with chronic heart failure. Respirology 2019, 24, 154-161. [CrossRef]

7. Hamazaki, N.; Kamiya, K.; Matsuzawa, R.; Nozaki, K.; Ichikawa, T.; Tanaka, S.; Nakamura, T.; Yamashita, M.; Maekawa, E.; Noda, C.; et al. Prevalence and prognosis of respiratory muscle weakness in heart failure patients with preserved ejection fraction. Respir. Med. 2019, 161, 105834. [CrossRef]

8. Ponikowski, P.; Voors, A.A.; Anker, S.D.; Bueno, H.; Cleland, J.G.F.; Coats, A.J.S.; Falk, V.; Gonzalez-Juanatey, J.R.; Harjola, V.P.; Jankowska, E.A.; et al. 2016 ESC Guidelines for the diagnosis and treatment of acute and chronic heart failure: The Task Force for the diagnosis and treatment of acute and chronic heart failure of the European Society of Cardiology (ESC)Developed with the special contribution of the Heart Failure Association (HFA) of the ESC. Eur. Heart J. 2016, 37, 2129-2200. [CrossRef]

9. Smart, N.A.; Giallauria, F.; Dieberg, G. Efficacy of inspiratory muscle training in chronic heart failure patients: A systematic review and meta-analysis. Int. J. Cardiol. 2013, 167, 1502-1507. [CrossRef]

10. Piepoli, M.F.; Hoes, A.W.; Agewall, S.; Albus, C.; Brotons, C.; Catapano, A.L.; Cooney, M.T.; Corra, U.; Cosyns, B.; Deaton, C.; et al. 2016 European Guidelines on cardiovascular disease prevention in clinical practice: The Sixth Joint Task Force of the European Society of Cardiology and Other Societies on Cardiovascular Disease Prevention in Clinical Practice (constituted by representatives of 10 societies and by invited experts)Developed with the special contribution of the European Association for Cardiovascular Prevention \& Rehabilitation (EACPR). Eur. Heart J. 2016, 37, 2315-2381. [CrossRef]

11. Habedank, D.; Meyer, F.J.; Hetzer, R.; Anker, S.D.; Ewert, R. Relation of respiratory muscle strength, cachexia and survival in severe chronic heart failure. J. Cachexia Sarcopenia Muscle 2013, 4, 277-285. [CrossRef] [PubMed]

12. Izawa, H.; Yoshida, T.; Ikegame, T.; Izawa, K.P.; Ito, Y.; Okamura, H.; Osada, N.; Kinugawa, S.; Kubozono, T.; Kono, Y.; et al. Standard Cardiac Rehabilitation Program for Heart Failure. Circ. J. 2019, 83, 2394-2398. [CrossRef] [PubMed]

13. Chen, Y.J.; Sung, S.H.; Cheng, H.M.; Huang, W.M.; Wu, C.L.; Huang, C.J.; Hsu, P.F.; Yeh, J.S.; Guo, C.Y.; Yu, W.C.; et al. Performance of AHEAD Score in an Asian Cohort of Acute Heart Failure With Either Preserved or Reduced Left Ventricular Systolic Function. J. Am. Heart Assoc. 2017, 6, e004297. [CrossRef] 
14. ATS Committee on Proficiency Standards for Clinical Pulmonary Function Laboratories. ATS statement: Guidelines for the six-minute walk test. Am. J. Respir. Crit. Care Med. 2002, 166, 111-117. [CrossRef] [PubMed]

15. Tojo, N.; Suga, H.; Kambe, M. Lung function testing-The Official Guideline of the Japanese Respiratory Society. Rinsho Byori 2005, 53, 77-81.

16. American Thoracic Society; European Respiratory Society. ATS/ERS Statement on respiratory muscle testing. Am. J. Respir. Crit. Care Med. 2002, 166, 518-624. [CrossRef]

17. Suzuki, M.; Teramoto, S.; Sudo, E.; Ogawa, K.; Namekawa, T.; Motrita, K.; Matsuse, T.; Takizawa, H.; Ouchi, Y.; Fukuchi, Y. Age-related changes in static maximal inspiratory and expiratory pressures. Nihon Kyobu Shikkan Gakkai Zasshi 1997, 35, 1305-1311.

18. Hughes, P.D.; Polkey, M.I.; Harris, M.L.; Coats, A.J.S.; Moxham, J.; Green, M. Diaphragm strength in chronic heart failure. Am. J. Respir. Crit. Care Med. 1999, 160, 529-534. [CrossRef]

19. Group JCSJW. Guidelines for rehabilitation in patients with cardiovascular disease (JCS 2012). Circ. J. 2014, 78, 2022-2093. [CrossRef]

20. Piepoli, M.F.; Conraads, V.; Corra, U.; Dickstein, K.; Francis, D.P.; Jaarsma, T.; McMurray, J.; Pieske, B.; Piotrowicz, E.; Schmid, J.P.; et al. Exercise training in heart failure: From theory to practice. A consensus document of the Heart Failure Association and the European Association for Cardiovascular Prevention and Rehabilitation. Eur. J. Heart Fail. 2011, 13, 347-357. [CrossRef]

21. Meyer, F.J.; Borst, M.M.; Zugck, C.; Kirschke, A.; Schellberg, D.; Kubler, W.; Haass, M. Respiratory muscle dysfunction in congestive heart failure: Clinical correlation and prognostic significance. Circulation 2001, 103, 2153-2158. [CrossRef] [PubMed]

22. Iversen, K.K.; Kjaergaard, J.; Akkan, D.; Kober, L.; Torp-Pedersen, C.; Hassager, C.; Vestbo, J.; Kjoller, E.; Group, E.L.F.S. The prognostic importance of lung function in patients admitted with heart failure. Eur. J. Heart Fail. 2010, 12, 685-691. [CrossRef] [PubMed]

23. Chuang, M.L.; Lin, I.F.; Hsieh, M.J. More Impaired Dynamic Ventilatory Muscle Oxygenation in Congestive Heart Failure than in Chronic Obstructive Pulmonary Disease. J. Clin. Med. 2019, 8, 1641. [CrossRef] [PubMed]

24. Moreno, A.M.; Toledo-Arruda, A.C.; Lima, J.S.; Duarte, C.S.; Villacorta, H.; Nobrega, A.C.L. Inspiratory Muscle Training Improves Intercostal and Forearm Muscle Oxygenation in Patients With Chronic Heart Failure: Evidence of the Origin of the Respiratory Metaboreflex. J. Card. Fail. 2017, 23, 672-679. [CrossRef]

25. Chiappa, G.R.; Roseguini, B.T.; Vieira, P.J.; Alves, C.N.; Tavares, A.; Winkelmann, E.R.; Ferlin, E.L.; Stein, R.; Ribeiro, J.P. Inspiratory muscle training improves blood flow to resting and exercising limbs in patients with chronic heart failure. J. Am. Coll. Cardiol. 2008, 51, 1663-1671. [CrossRef]

26. Del Buono, M.G.; Arena, R.; Borlaug, B.A.; Carbone, S.; Canada, J.M.; Kirkman, D.L.; Garten, R.; Rodriguez-Miguelez, P.; Guazzi, M.; Lavie, C.J.; et al. Exercise Intolerance in Patients With Heart Failure: JACC State-of-the-Art Review. J. Am. Coll. Cardiol. 2019, 73, 2209-2225. [CrossRef]

27. Jaenisch, R.B.; Hentschke, V.S.; Quagliotto, E.; Cavinato, P.R.; Schmeing, L.A.; Xavier, L.L.; Dal Lago, P. Respiratory muscle training improves hemodynamics, autonomic function, baroreceptor sensitivity, and respiratory mechanics in rats with heart failure. J. Appl. Physiol. (1985) 2011, 111, 1664-1670. [CrossRef]

28. Tager, T.; Hanholz, W.; Cebola, R.; Frohlich, H.; Franke, J.; Doesch, A.; Katus, H.A.; Wians, F.H., Jr.; Frankenstein, L. Minimal importance for 6-minute walk test distances among patients with chronic heart failure. Int. J. Cardiol. 2014, 176, 94-98. [CrossRef]

29. Clark, A.L.; Kalra, P.R.; Petrie, M.C.; Mark, P.B.; Tomlinson, L.A.; Tomson, C.R.V. Change in renal function associated with drug treatment in heart failure: National guidance. Heart 2019, 105, 904-910. [CrossRef]

30. Dall'Ago, P.; Chiappa, G.R.; Guths, H.; Stein, R.; Ribeiro, J.P. Inspiratory muscle training in patients with heart failure and inspiratory muscle weakness: A randomized trial. J. Am. Coll. Cardiol. 2006, 47, 757-763. [CrossRef]

(C) 2020 by the authors. Licensee MDPI, Basel, Switzerland. This article is an open access article distributed under the terms and conditions of the Creative Commons Attribution (CC BY) license (http://creativecommons.org/licenses/by/4.0/). 